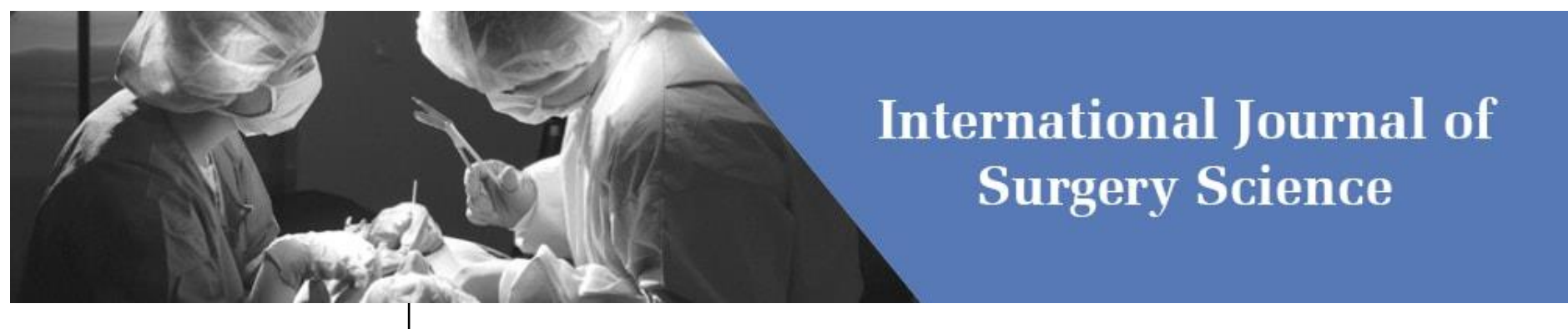

E-ISSN: 2616-3470

P-ISSN: 2616-3462

(c) Surgery Science

www.surgeryscience.com

2019; 3(1): 330-336

Received: 14-11-2018

Accepted: 18-12-2018

Dr. Geeta K Avadhani

Professor, Unit Chief, Department of General Surgery,

Adichunchanagiri Institute of

Medical Sciences, BG Nagara,

Karnataka, India

Dr. Dharanesh B

Post Graduate, Department of General Surgery, Adichunchanagiri

Institute of Medical Sciences, BG

Nagara, Karnataka, India

\section{Changes in liver function test after laparoscopic surgery}

\author{
Dr. Geeta K Avadhani and Dr. Dharanesh B
}

DOI: https://doi.org/10.33545/surgery.2019.v3.i1f.56

\begin{abstract}
Introduction: In this modern era Laparoscopic surgery has evoked marked changes in approach to surgical diseases. The "Minimally invasive surgery "(MIS), now turned into "Minimal Access Surgery" (MAS) has prompted us to prompted us to perform most of the operations by Laparoscopic technique. Main advantages of laparoscopic surgery include; reduction of tissue trauma due to small skin incisions and reduction in adhesion formation. All Laparoscopic procedures are usually performed by creating pneumoperitoneum. Carbon dioxide is most commonly used inert gas to create pneumoperitoneum. Apart from many advantages in Laparoscopic procedures; effects of pneumoperitoneum on the cardiovascular and respiratory system resulting in several pathophysiological changes in the patients have been reported. Recently many studies have disclosed 'unexplained' changes in postoperative liver function tests in patients undergoing laparoscopic procedures. These studies demonstrate that transient elevation of hepatic enzymes could occur after laparoscopic procedures. No causes for this elevation are documented so far. $\mathrm{CO} 2$ pneumoperitoneum might be one of the main reasons for the change of serum liver enzymes. So we decided to perform a study to correlate the changes in serum liver enzymes pre-operative and post operation.
\end{abstract}

Aim and Objective: The purpose of this study was to investigate the effect of laparoscopic surgeries on liver function test and the possible mechanisms behind such effect in our hospital in the Department of General Surgery at Sri Adichunchanagiri Hospital and Research Center (AH \& RC), the teaching hospital attached to Adichunchanagiri Institute of Medical Sciences, B.G. Nagara, Mandya by statistical analysis.

Material and Methods: This was a prospective study conducted in 100 patients who were undergoing various types of laparoscopic surgery performed using $\mathrm{CO} 2$ to create pneumoperitoneum under intraperitoneal pressure of $12-14 \mathrm{mmHg}$ during the period of 18 months from January 2017 to June 2018 in our Hospital. Blood sampling were collected both preoperatively and post operatively on day 1 and day 5 for liver function tests along with routine investigations.

Result: The level of serum bilirubin, serum aspartate amino transferase, serum alanine amino transferase and alkaline phosphatase increased significantly during the first 24 hours post operatively. These values returned to near pre-operative value by post-operative day 5 .

Interpretation and Conclusion: In this study we conclude that there was a transient changes in serum Bilirubin and Liver Enzymes in the POD-1 which reverted back to near normal to the pre-operative level by POD-5. There was no complication, no morbidity and no mortality. It is concluded that the changes in LFT is probably due to $\mathrm{CO} 2$ pneumoperitoneum. Laparoscopic procedures can be done safely in a patient in the presence of normal Liver function test and may not be safe in presence of serious Liver disorder.

Keywords: liver, function test, laparoscopic surgery

\section{Introduction}

In this modern era Laparoscopic surgery has evoked marked changes in approach to surgical diseases. The "Minimally invasive surgery "(MIS), now turned into "Minimal Access Surgery" (MAS) has prompted us to prompted us to perform most of the operations by Laparoscopic technique. Main advantages of laparoscopic surgery include; reduction of tissue trauma due to small skin incisions and reduction in adhesion formation. The growing interest in laparoscopy is mostly attributable to cumulative evidence suggesting a reduction in patient morbidity, shortening of duration of hospital stay and early return to normal activity.

All Laparoscopic procedures are usually performed by creating pneumoperitoneum. Carbon dioxide is most commonly used inert gas to create pneumoperitoneum as it has got many advantages like non-combustibility, high diffusibility, rapid rate of absorption and excretion via the lungs. CO2 is 20 times more soluble in serum than room air or oxygen, also it has been shown to be absorbed 32 times more quickly than room air when used for double contrast Barium enemas. During most cases of the Laparoscopic surgery, a pneumoperitoneum of 12-14
Dr. Geeta K Avadhani

Professor, Unit Chief, Department of General Surgery,

Adichunchanagiri Institute of

Medical Sciences, BG Nagara,

Karnataka, India 
$\mathrm{mm} \mathrm{Hg} \mathrm{CO} 2$ is established. Apart from many advantages in Laparoscopic procedures; effects of pneumoperitoneum on the cardiovascular and respiratory system resulting in several pathophysiological changes in the patients have been reported. Recently many studies have disclosed 'unexplained' changes in postoperative liver function tests in patients undergoing laparoscopic procedures. These studies demonstrate that transient elevation of hepatic enzymes could occur after laparoscopic procedures. No causes for this elevation are documented so far. These changes might be attributed to hepatocellular dysfunction secondary to one or combination of $\mathrm{CO} 2$ pneumoperitoneum, diathermy extruding liver, branch of the hepatic artery injured and general anesthesia. CO2 pneumoperitoneum might be one of the main reasons for the change of serum liver enzymes. So we decided to perform a study to correlate the changes in serum liver enzymes preoperative and post operation.

\section{Aims \& Objectives}

The aim of our study is to find

1. Age and Sex distribution of patients undergoing Laparoscopic Surgery.

2. To study the incidence of alterations in liver function following Laparoscopic surgery

\section{Material and Methods}

This is a prospective study conducted in the Department of General surgery at Adichunchanagiri Hospital and Research Center, the teaching hospital attached to Adichunchanagiri Institute of Medical Sciences, B.G. Nagara during the period of 18 months from January 2017 to June 2018.

The changes in Liver function test in 100 patients undergoing Laparoscopic Surgeries performed using $\mathrm{CO} 2$ to create pneumoperitoneum under intraperitoneal pressure of 12$14 \mathrm{mmHg}$ are being studied.

Blood sampling for liver function tests were collected both preoperatively and post operatively on day 1 and day 5 by comparing the level of serum bilirubin, serum alanine amino transferase (ALT), serum aspartate amino transferase (AST) and serum alkaline phosphatase (ALP). The time duration of carbondioxide insufflation was also measured.

\section{Sample size}

The sample size was of 100 patients admitted in the Department of General Surgery, at Adichunchanagiri Hospital \& Research Center, the teaching hospital attached to Adichunchanagiri Institute of Medical Sciences, B.G. Nagara for laparoscopic cholecystectomy or appendicectomy or umbalical hernia mesh repair.

\section{Ethical committee clearance}

The study was started only after obtaining clearence from the Institutional Ethical committee, Adichunchanagiri Institute of Medical Sciences, B.G. Nagara, Mandya Dist., Karnataka571448.

\section{Inclusion criteria}

- Patients between the age group of 18 to 70 Years of both sexes.

- Patients undergoing laparoscopic surgery- Laparoscopic Appendicectomy, Laparoscopic cholecystectomy and Laparoscopic umbilical hernia mesh repair.

- The patients who will give written consent to be part of the study group.

\section{Exclusion criteria}

- Patients below 18 years and above 70 years of age.

- Any patient with abnormal Liver Function Test.

- Patients with severe co-morbid conditions like CardioRespiratory and Renal disease.

- Immuno compromised Patients.

- Patients with Jaundice.

- Suspected chronic liver diseases

- Common bile duct pathology

- Conversion to open Surgery

- Hematological Disorders

- Patients who develop biliary complications.

- Patients who have undergone ERCP within one week before surgery.

- Patients who are recently treated for Pancreatitis.

\section{Data collected includes}

- Name, Age, Sex, In Patient no. (IP No), Investigation and Diagnosis.

- Along with routine investigation report, the reports of LFT done preoperatively and postoperative day $1 \& 5$

- Time of start and completion of the procedure.

- Duration of Pneumoperitoneum.

- Any intraoperative complications.

\section{Plan for data analysis}

- Demographic data were presented in mean \& SD.

- All LFT parameters (Total Bilirubin, Direct Bilirubin, SGOT, SGPT, Alkaline phosphatase) and length of hospital stay was presented in mean \& SD.

- Data will be analyzed for finding the significance of effect of laparoscopy on hepatic function by using student paired $t$ test.

\section{Results}

All cases were evaluated clinically, only essential investigations necessary for diagnosis and preoperative assessment were carried out before operations. In all patients LFT carried out pre operatively and on post-operative Day-1 \& Day-5. The patients of both sexes and of age group from 18-70 years were included in the study. The results obtained were recorded in the proforma prepared for the study and were analysed as follows.

Data was entered into Microsoft excel data sheet and was analyzed using SPSS 20 version software. Categorical data was represented in the form of frequencies and proportions. Continuous data was represented as mean and standard deviation and $\mathrm{p}$ value was calculated using Paired test. Repeated measures of ANOVA Test were used to check the overall Association between the three groups.

MS Excel and MS word was used to obtain various types of graphs such as bar diagram, Pie diagram. p value (Probability that the result is true) of $<0.05$ was considered as statistically significant after assuming all the rules of statistical tests. MS Excel, SPSS version 20 (IBM SPSS Statistics, Somers NY, USA) was used to analyze data.

Table 1: Age wise distribution of Study subjects

\begin{tabular}{|c|c|c|c|}
\hline \multicolumn{1}{|c|}{} & Count & Column N \% \\
\hline \multirow{4}{*}{ Age group } & Less than 20 years & 4 & $4.0 \%$ \\
\cline { 2 - 4 } & $21-30$ Years & 29 & $29.0 \%$ \\
\cline { 2 - 4 } & $31-40$ Years & 22 & $22.0 \%$ \\
\cline { 2 - 4 } & $41-50$ Years & 22 & $22.0 \%$ \\
\cline { 2 - 4 } & 51-60 Years & 12 & $12.0 \%$ \\
\cline { 2 - 4 } & More than 60 Years & 11 & $11.0 \%$ \\
\hline
\end{tabular}




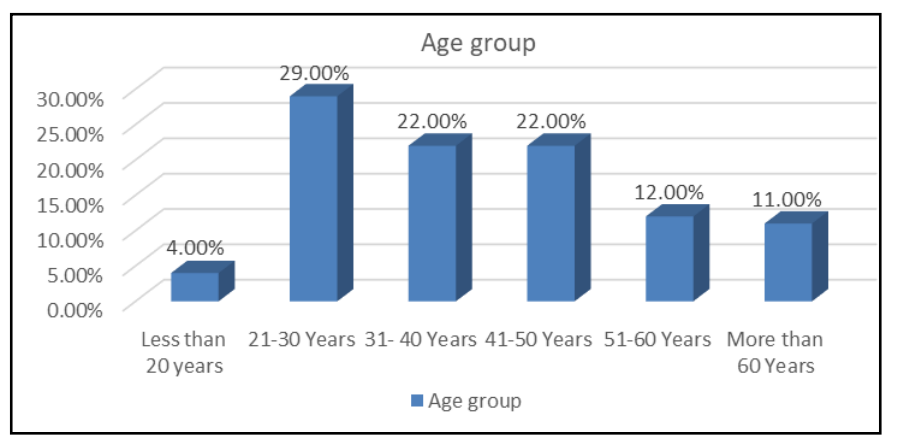

Fig 1: Age wise distribution of study subjects

In our study majority of the subjects were in 20 to 50 years of age group. Only 4 cases were less than 20 years and 11 cases were seen in subjects above 60 years of the age.

Table 2: Gender wise distribution of study subjects

\begin{tabular}{|c|c|c|c|}
\hline \multicolumn{2}{|c|}{} & Count & Column N \% \\
\hline \multirow{2}{*}{ Gender } & Female & 57 & $57.0 \%$ \\
\cline { 2 - 4 } & Male & 43 & $43.0 \%$ \\
\hline
\end{tabular}

Nearly $57 \%$ of the study participants were Female and $43 \%$ of Male were present in our study.

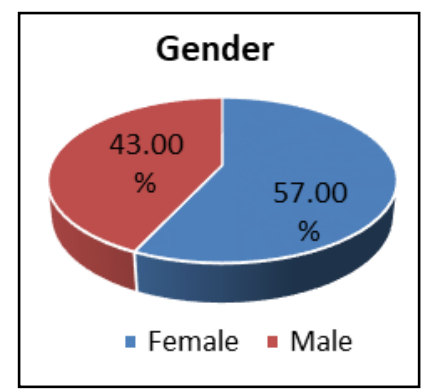

Fig 2: Gender wise distribution of Subjects
Table 3: Diagnosis of Cases

\begin{tabular}{|c|c|c|c|}
\hline \multicolumn{2}{|c|}{} & Count & Column N \% \\
\hline \multirow{3}{*}{ Diagnosis } & Appendicitis & 18 & $18.0 \%$ \\
\cline { 2 - 4 } & Cholelithiasis & 72 & $72.0 \%$ \\
\cline { 2 - 4 } & Umbilical Hernia & 10 & $10.0 \%$ \\
\hline
\end{tabular}

In our study, Majority (72\%) of the cases were diagnosed with Cholelithiasis, $18 \%$ of the cases were Appendicitis and $10 \%$ of Umbilical Hernias, who have undergone laparoscopic procedures.

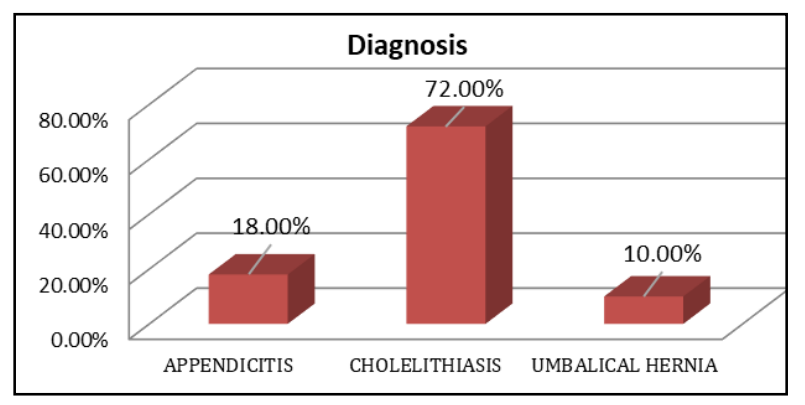

Fig 3: Diagnosis of the cases

Table 4: Mean $\mathrm{CO} 2$ Pressure used in the procedure

\begin{tabular}{|c|c|c|}
\hline & Mean & Standard Deviation \\
\hline $\mathrm{CO} 2$ Pressure Used $(\mathrm{mm}$ of $\mathrm{Hg})$ & 14 & 1 \\
\hline
\end{tabular}

The mean pressure of carbon dioxide used in our study was 14 $\mathrm{mm}$ of $\mathrm{Hg}$ with Standard deviation of $1 \mathrm{~mm}$ of $\mathrm{Hg}$.

Table 5: Mean Duration of Surgery

\begin{tabular}{|c|c|c|}
\hline & Mean & Standard Deviation \\
\hline Duration of Surgery (Min) & 99 & 22 \\
\hline
\end{tabular}

The mean total time taken to complete the surgery was 99 mins with standard deviation of $22 \mathrm{~min}$.

Table 6: Mean Distribution of Liver function test Values on Preoperative day, Post-operative Day 1 and Day 5.

\begin{tabular}{|c|c|c|c|c|c|c|c|c|c|c|c|}
\hline & & \multicolumn{2}{|c|}{ Total Bilirubin } & \multicolumn{2}{|c|}{ Direct Bilirubin } & \multicolumn{2}{|c|}{ SGOT } & \multicolumn{2}{|c|}{ SGPT } & \multicolumn{2}{|c|}{ ALP } \\
\hline & & Mean & SD & Mean & SD & Mean & SD & Mean & SD & Mean & SD \\
\hline \multirow{3}{*}{ Group } & Pre OP & 0.58 & 0.29 & 0.22 & 0.10 & 34.8 & 10.9 & 31.5 & 11.2 & 78.9 & 17.3 \\
\hline & POD 1 & 0.73 & 0.23 & 0.23 & 0.09 & 61.1 & 14.1 & 60.6 & 15.2 & 98.1 & 14.2 \\
\hline & POD 5 & 0.44 & 0.18 & 0.15 & 0.06 & 34.8 & 9.1 & 32.2 & 9.2 & 76.2 & 12.7 \\
\hline
\end{tabular}

\begin{tabular}{|l|l|l|l|l|l|l|}
\hline Repeated Measures of ANOVA & $\mathrm{F}=690.377 \mathrm{P}=0.000$ & $\mathrm{~F}=534.65 \mathrm{P}=0.000$ & $\mathrm{~F}=1797.88 \mathrm{P}=0.000$ & $\mathrm{~F}=1562.64 \mathrm{P}=0.000$ & $\mathrm{~F}=4598.58 \mathrm{P}=0.000$ \\
\hline
\end{tabular}

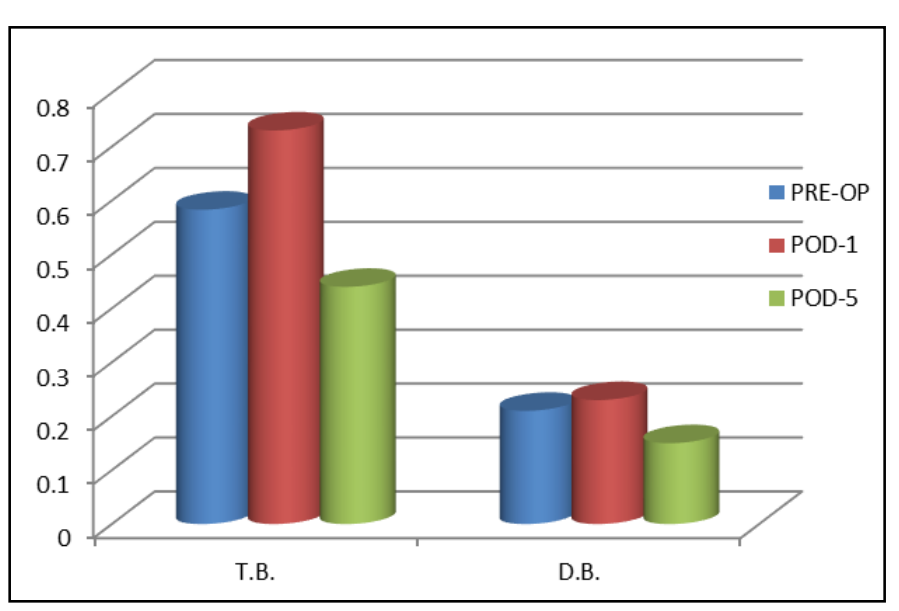

Fig 4: Changes in Serum Bilirubin after laparoscopic surgery

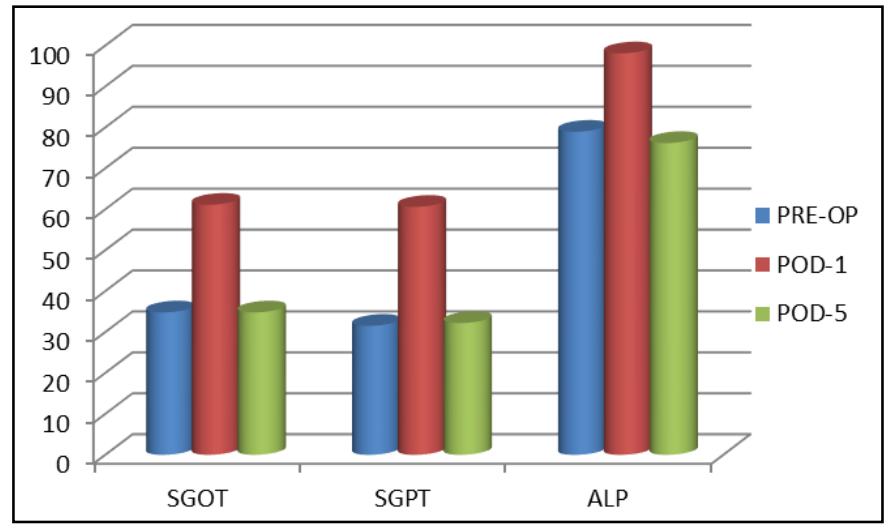

Fig 5: Changes in Liver Enzymes after laparoscopic surgery

In figures $4 \& 5$, when compared to the pre-operative values, 
mean values of serum bilirubin, AST, ALT and ALP increased significantly $(\mathrm{p}<0.001)$ by post-operative day 1 and they came down to near pre-op values by post-op day 3 .

Table 7: Association of Total Bilirubin levels of Preoperative Day, Post-operative Day $1 \& 5$

\begin{tabular}{|c|c|c|}
\hline & Paired T test value & Inference \\
\hline Pre OP Total Bilirubin and POD 1 Total Bilirubin & -8.545 & Highly Significant \\
\hline Pre OP Total Bilirubin and POD 5 Total Bilirubin & 9.252 & Non-Significant \\
\hline POD 1 Total Bilirubin and POD 5 Total Bilirubin & 19.707 & Highly Significant \\
\hline
\end{tabular}

In Table-7, the Mean Difference of Total bilirubin level was found to be statistically significant when compared between Preoperative day vs Post-operative Day1, and Post-operative
Day 1 vs Post-operative Day 5 but non-significant between Preoperative day vs Post-operative Day 5

Table 8: Association of Direct Bilirubin levels of Preoperative Day, Post-operative Day $1 \&$ Post-operative Day 5

\begin{tabular}{|c|c|c|}
\hline & Paired T test value & Inference \\
\hline Pre OP Direct Bilirubin and POD 1 Direct Bilirubin & -2.044 & Highly Significant \\
\hline Pre OP Direct Bilirubin and POD 5 Direct Bilirubin & 8.343 & Non-Significant \\
\hline POD 1 Direct Bilirubin and POD 5 Direct Bilirubin & 5.000 & Highly Significant \\
\hline
\end{tabular}

In Table-8, the Mean Difference of Direct bilirubin level was found to be statistically significant when compared between Preoperative day vs Post-operative Day 5 and between Post- operative Day 1 vs Post-operative Day 5. The mean Difference of Direct Bilirubin between Preoperative Day and Post-operative Day 1 was found to be non-significant statistically.

Table 9: Association of SGOT levels of Preoperative Day, Post-operative Day 1 and 5

\begin{tabular}{|c|c|c|}
\hline & Paired T test value & Inference \\
\hline Pre OP SGOT and POD 1 SGOT & -24.381 & Highly Significant \\
\hline Pre OP SGOT and POD 5 SGOT & 1.436 & Non-Significant \\
\hline POD 1 SGOT and POD 5 SGOT & 25.466 & Highly Significant \\
\hline
\end{tabular}

In Table-9, the Mean Difference of SGOT level was found to be statistically significant when compared between Preoperative day vs Post-operative Day 1 and between Post-operative Day 1 vs Post-operative Day 5. The mean Difference of SGOT between Preoperative Day and Post-operative Day 5 was found to be non-significant statistically.

Table 10: Association of SGPT levels of Preoperative Day, Post-operative Day 1 and 5

\begin{tabular}{|c|c|c|}
\hline & Paired T test value & Inference \\
\hline Pre OP SGPT and POD 1 SGPT & -24.640 & Highly Significant \\
\hline Pre OP SGPT and POD 5 SGPT & -1.022 & Non-Significant \\
\hline POD 1 SGPT and POD 5 SGPT & 23.241 & Highly Significant \\
\hline
\end{tabular}

In Table-10, the Mean Difference of SGPT level was found to be statistically significant when compared between Preoperative day vs Post-operative Day 1 and between Post-operative Day 1 vs Post-operative Day 5. The mean Difference of SGPT between Preoperative Day and Post-operative Day 5 was found to be non-significant statistically.

Table 11: Association of ALP levels of Preoperative Day, Post-operative Day 1 and 5

\begin{tabular}{|c|c|c|}
\hline & Paired T test value & Inference \\
\hline Pre OP ALP and POD 1 ALP & -10.866 & Highly Significant \\
\hline Pre OP ALP and POD 5 ALP & 2.733 & Non-Significant \\
\hline POD 1 ALP and POD 5 ALP & 15.516 & Highly Significant \\
\hline
\end{tabular}

In Table-11, the Mean Difference of ALP level was found to be statistically significant when compared between Preoperative day vs Post-operative Day1 and Post-operative Day 1 vs Postoperative Day 5 but non-significant between Preoperative day vs Post-operative Day 5.

Table 12: Discharge at Post-Op day

\begin{tabular}{|c|c|c|}
\hline Discharge (POD) & No. of Patients & Percent \\
\hline 2 & 3 & $3 \%$ \\
\hline 3 & 12 & $12 \%$ \\
\hline 4 & 26 & $26 \%$ \\
\hline 5 & 58 & $58 \%$ \\
\hline 6 & 1 & $1 \%$ \\
\hline
\end{tabular}

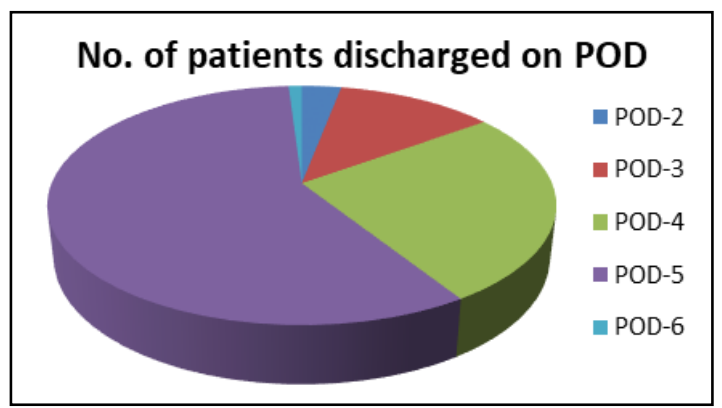

Fig 6: No. of patients discharged on POD

In Table-12 and Fig.6 shows patients got discharged on different post-operative days. 
Table 13: Correlation of CO 2 pressure with various parameters of LFT on Post-op Day 1 and Post-op Day 5

\begin{tabular}{|c|c|c|c|c|c|c|c|c|c|c|c|c|}
\hline \multicolumn{13}{|c|}{ Correlations } \\
\hline & & $\begin{array}{l}\text { CO2 PRESSURE } \\
\text { USED }(\mathrm{mm} \text { of } \mathrm{Hg})\end{array}$ & $\begin{array}{c}\text { POD 1 } \\
\text { TB }\end{array}$ & $\begin{array}{l}\text { POD } 1 \\
\text { DB }\end{array}$ & $\begin{array}{l}\text { POD 1 } \\
\text { SGOT }\end{array}$ & $\begin{array}{l}\text { POD 1 } \\
\text { SGPT }\end{array}$ & $\begin{array}{l}\text { POD 1 } \\
\text { ALP }\end{array}$ & $\begin{array}{c}\text { POD } 5 \\
\text { TB }\end{array}$ & $\begin{array}{l}\text { POD } 5 \\
\text { DB }\end{array}$ & $\begin{array}{l}\text { POD 5 } \\
\text { SGOT }\end{array}$ & $\begin{array}{l}\text { POD 5 } \\
\text { SGPT }\end{array}$ & $\begin{array}{l}\text { POD 5 } \\
\text { ALP }\end{array}$ \\
\hline \multirow{3}{*}{$\begin{array}{l}\text { CO2 PRESSURE } \\
\text { USED }(\mathrm{mm} \text { of } \mathrm{Hg})\end{array}$} & Pearson Correlation & 1 & .103 & -.122 & -.071 & $-.230^{*}$ & $-.238^{*}$ & .141 & .111 & -.136 & $-.230^{*}$ & -.047 \\
\hline & Sig. (2-tailed) & & .309 & .229 & .484 & .022 & .017 & .160 & .270 & .179 & .021 & .640 \\
\hline & $\mathrm{N}$ & 100 & 100 & 100 & 100 & 100 & 100 & 100 & 100 & 100 & 100 & 100 \\
\hline \multirow{3}{*}{ POD 1 TB } & Pearson Correlation & .103 & 1 & $.239^{*}$ & .060 & -.072 & .096 & $.773^{* * *}$ & $.585^{* *}$ & .175 & -.018 & -.169 \\
\hline & Sig. (2-tailed) & .309 & & .017 & .555 & .475 & .344 & .000 & .000 & .082 & .855 & .092 \\
\hline & $\mathrm{N}$ & 100 & 100 & 100 & 100 & 100 & 100 & 100 & 100 & 100 & 100 & 100 \\
\hline \multirow{3}{*}{ POD 1 DB } & Pearson Correlation & -.122 & $.239^{*}$ & 1 & .065 & -.061 & $.266^{* *}$ & .138 & .124 & .104 & -.015 & -.090 \\
\hline & Sig. (2-tailed) & .229 & .017 & & .520 & .549 & .008 & .173 & .221 & .303 & .879 & .375 \\
\hline & $\mathrm{N}$ & 100 & 100 & 100 & 100 & 100 & 100 & 100 & 100 & 100 & 100 & 100 \\
\hline \multirow{3}{*}{ POD 1 SGOT } & Pearson Correlation & -.071 & .060 & .065 & 1 & $.381^{\text {** }}$ & .140 & -.011 & -.013 & $.653^{* *}$ & .165 & .049 \\
\hline & Sig. (2-tailed) & .484 & .555 & .520 & & .000 & .165 & .916 & .899 & .000 & .101 & .629 \\
\hline & $\mathrm{N}$ & 100 & 100 & 100 & 100 & 100 & 100 & 100 & 100 & 100 & 100 & 100 \\
\hline \multirow{3}{*}{ POD 1 SGPT } & Pearson Correlation & $-.230^{*}$ & -.072 & -.061 & $.381^{* * *}$ & 1 & $.255^{*}$ & $-.229^{*}$ & -.115 & $.209^{*}$ & $.593^{* *}$ & .125 \\
\hline & Sig. (2-tailed) & .022 & .475 & .549 & .000 & & .010 & .022 & .253 & .037 & .000 & .216 \\
\hline & $\mathrm{N}$ & 100 & 100 & 100 & 100 & 100 & 100 & 100 & 100 & 100 & 100 & 100 \\
\hline \multirow{3}{*}{ POD 1 ALP } & Pearson Correlation & $-.238^{*}$ & .096 & $.266^{* *}$ & .140 & $.255^{*}$ & 1 & .042 & .101 & .165 & .170 & $.465^{* *}$ \\
\hline & Sig. (2-tailed) & .017 & .344 & .008 & .165 & .010 & & .679 & .318 & .101 & .091 & .000 \\
\hline & $\mathrm{N}$ & 100 & 100 & 100 & 100 & 100 & 100 & 100 & 100 & 100 & 100 & 100 \\
\hline \multirow{3}{*}{ POD 5 TB } & Pearson Correlation & .141 & $.773^{* *}$ & .138 & -.011 & $-.229^{*}$ & .042 & 1 & $.733^{* *}$ & .104 & -.120 & -.098 \\
\hline & Sig. (2-tailed) & .160 & .000 & .173 & .916 & .022 & .679 & & .000 & .303 & .236 & .331 \\
\hline & $\mathrm{N}$ & 100 & 100 & 100 & 100 & 100 & 100 & 100 & 100 & 100 & 100 & 100 \\
\hline \multirow{3}{*}{ POD 5 DB } & Pearson Correlation & .111 & $.585^{* *}$ & .124 & -.013 & -.115 & .101 & $.733^{* *}$ & 1 & .119 & .066 & -.159 \\
\hline & Sig. (2-tailed) & .270 & .000 & .221 & .899 & .253 & .318 & .000 & & .237 & .513 & .114 \\
\hline & $\mathrm{N}$ & 100 & 100 & 100 & 100 & 100 & 100 & 100 & 100 & 100 & 100 & 100 \\
\hline \multirow{3}{*}{ POD 5 SGOT } & Pearson Correlation & -.136 & .175 & .104 & $.653^{* * *}$ & $.209^{*}$ & .165 & .104 & .119 & 1 & $.320^{* *}$ & .003 \\
\hline & Sig. (2-tailed) & .179 & .082 & .303 & .000 & .037 & .101 & .303 & .237 & & .001 & .975 \\
\hline & $\mathrm{N}$ & 100 & 100 & 100 & 100 & 100 & 100 & 100 & 100 & 100 & 100 & 100 \\
\hline \multirow{3}{*}{ POD 5 SGPT } & Pearson Correlation & $-.230^{*}$ & -.018 & -.015 & .165 & $.593^{* *}$ & .170 & -.120 & .066 & $.320^{* *}$ & 1 & .072 \\
\hline & Sig. (2-tailed) & .021 & .855 & .879 & .101 & .000 & .091 & .236 & .513 & .001 & & .475 \\
\hline & $\mathrm{N}$ & 100 & 100 & 100 & 100 & 100 & 100 & 100 & 100 & 100 & 100 & 100 \\
\hline \multirow{3}{*}{ POD 5 ALP } & Pearson Correlation & -.047 & -.169 & -.090 & .049 & .125 & $.465^{* *}$ & -.098 & -.159 & .003 & .072 & 1 \\
\hline & Sig. (2-tailed) & .640 & .092 & .375 & .629 & .216 & .000 & .331 & .114 & .975 & .475 & \\
\hline & $\mathrm{N}$ & 100 & 100 & 100 & 100 & 100 & 100 & 100 & 100 & 100 & 100 & 100 \\
\hline
\end{tabular}

*. Correlation is significant at the 0.05 level (2-tailed).

**. Correlation is significant at the 0.01 level (2-tailed).

The pressure of $\mathrm{CO} 2$ Used in the laparoscopy surgery was found to be Positively Correlated with Total bilirubin on both Day 1 and 5, Direct Bilirubin on Day 5 and all the other Liver function test enzymes.

From this study we have observed that the disturbances in liver function tests are not related to the age or sex in relation to laparoscopy. Carbon dioxide pneumoperitoneum, one of the main common factor which is used in all laparoscopic procedures done in my study might be one of the major causative factors.

\section{Discussion}

Laparoscopic surgery has become the established method of treatment for many surgical conditions. The progress in laparoscopic procedures has largely been due to the technological advances in endoscopic optics, video cameras and endoscopic instrumentation. Smaller incisions, reduced postoperative pain, shorter hospital stay, early ambulation and return to work are some of the advantages that increased the popularity of laparoscopic procedures. Also from past decades, many studies disclosed unexplained changes in LFT in patients undergoing laparoscopic procedures. This may be due to $\mathrm{CO} 2$ pneumoperitoneum created while performing Lap procedures.

There are not many studies in our setting, to evaluate the potential deleterious effects of $\mathrm{CO} 2$ pneumoperitoneum on Liver function. This study is therefore intended to assess the clinical significance of unexplained disturbances in liver enzymes following laparoscopic surgeries. The post-operative increase seen in the levels of serum bilirubin and liver enzymes was transient and occurred irrespective of the type of laparoscopic surgery they underwent. The values returned to near preoperative levels within 5 days of surgery. None of the patients presented with post-operative clinical hepatic dysfunction in the follow up period. The Mean Difference of Total bilirubin level, direct bilirubin, SGOT, SGPT \& ALP were found to be statistically significant when compared between Preoperative day vs Post-operative Day-1. The first factor to be considered here is carbon dioxide pneumoperitoneum. All the patients in our study were subjected to carbon dioxide pneumoperitoneum and they showed changes in post-operative serum liver enzymes level. This is consistent with the results of other similar studies. The intra-abdominal pressure of $12-14 \mathrm{mmHg}$ used in our study was higher than the normal portal venous pressure of 7 $10 \mathrm{mmHg}$. This might cause a reduction in portal blood flow and lead to alterations in liver function.

The local effect of prolonged use of diathermy to the liver surface in laparoscopic cholecystectomy and the spread of heat to liver parenchyma may be another possibility ${ }^{1}$. This hypothesis is supported by some studies. However, it remains to be explained why there is hepatic enzyme elevation in laparoscopic surgeries where the focus is far away from the liver. Tauro LF, Sheethal CM et.al ${ }^{2}$ explained the squeeze pressure effect on the liver may be another possible mechanism for alterations of serum liver enzymes after laparoscopic cholecystectomy. The traction of the gall bladder may free the liver enzymes into the blood stream. But it is not significant as similar changes are seen in other laparoscopic surgeries like appendicectomy and hernia repairs, where the liver was not handled at all. Rikki Singal et al. 
[3] in their study they have mentioned an intra-abdominal pressure which is created during pneumoperitoneum of 12-14 $\mathrm{mmHg}$ is higher than normal portal blood pressure of 7-10 $\mathrm{mmHg}$, and is therefore capable of reducing portal blood flow and of causing alteration of the hepatic function. From this study we have observed that the disturbances in liver function tests are not related to the age or sex in relation to laparoscopy. It was thought that changes in LFT after laparoscopic cholecystectomy might be due to the squeeze pressure effect on the liver, the traction \& shearing effect of the gall bladder. In our study also it showed increase in Serum Bilirubin \& Liver enzymes after Laparoscopic Appendicectomy, Laparoscopic Umbilical Hernia mesh repair as well as in Laparoscopic cholecystectomy These changes in the Serum Bilirubin \& Liver enzymes may be due to the Pneumoperitoneum rather than thermal injury to the liver, shearing force to gall bladder which will not occur in Laparoscopic Appendicectomy \& Laparoscopic Umbilical Hernia mesh repair. Pneumoperitoneum is the common factor in all these three procedures, which may be the cause for these changes in Serum Bilirubin and Liver Enzymes. These similar changes are observed in Halvey A et al ${ }^{[4]}$. in their study and they concluded that low pressure pneumoperitoneum causes lesser side effects on liver function.

Min Tan, Feng Feng Xu, Peng JS et.al ${ }^{[5]}$ in his study compared the preoperative and postoperative changes in AST between open and laparoscopic cholecystectomy (LC) as well as open and laparoscopic colorectal cancer resection (LCR) in 286 patients. The levels of serum SGOT and SGPT raised symbolically within 24-48 hours following LC and LCR whereas both open surgeries had normal levels and this was attributed to $\mathrm{C} 02$ pneumoperitoneum. In 2005 a study by George Sakorafas ${ }^{[6]}$, concluded that 24 hours after the procedure SGOT and SGPT raised statistically significant. Levels returned to normality occurred 7-10 days after the procedure. ALT $(24,87.1$ +/- 24.2 U/L, P <.001) AST (24, 82.8 +/- 19.1, P<.001). In 2005, a study by Guven $\mathrm{HE}^{[7]}$ performed in 86 patients who underwent LC to investigate the alterations in serum enzymes levels. He concluded that the differences between elevations of enzymes levels were significant for LC. Tauro LF, Sheethal CM et.al ${ }^{[1]}$ Evaluation of effects of laparoscopic surgery on hepatic function in the year 2008, concluded that all types of laparoscopic procedures can cause transient elevation of hepatic enzymes and serum bilirubin for which $\mathrm{C} 02$ pneumoperitoneum is the causative factor. Halevy et.al first studied alterations in liver enzymes after laparoscopic surgeries. The possible mechanism included increased intra-abdominal pressure, squeeze pressure effect on the liver, pulling on the gall bladder, excessive use of diathermy". Vast investigation was done to evaluate the causes of this elevation and concluded that low pressure pneumoperitoneum was combined with lesser side effects on liver function. Syed Ibrahim et al. ${ }^{[8]}$, in his study on 60 patients, noticed The level of serum bilirubin, serum aspartate amino transferase, serum alanine amino transferase and alkaline phosphatase increased significantly during the first 24 hours post operatively. Doubling of pre-op values of AST was seen in $46 \%$, ALT in $32 \%$ and S. Bilirubin in $35 \%$ patients. These values returned to near pre-operative value by the 7 th day post operation. They concluded that there was a transient elevation of hepatic enzymes after laparoscopic surgery and major causative factor would be the $\mathrm{CO} 2$ pneumoperitoneum.

The pneumoperitoneum pressure was above than the pressure in portal venous system which is used for laparoscopic procedure. This pressure disrupts portal circulation and decreases portal flow up to $50 \%$, which causes abasement of the hepatic reticular endothelial system [9]. In our study also, the time of $\mathrm{C} 02$ pneumoperitoneum increased, there is elevation of intraabdominal pressure resulting in increased levels of serum liver enzymes and is the causative factor. The elevation and depression of intra-abdominal pressure in a small period during the laparoscopic surgery efficacy also be innovative as the sudden alteration of intra-abdominal pressure would affect the portal blood flow. This re-creation of blood flow and organs would lead to ischemia and re-creation damage of organs and tissues, mainly the kupffer and endothelial cells of hepatic sinusoids". This can cause free-radical generation". The reperfusion relevant system after laparoscopy and the generation of free radicals are however smaller than open surgery.

These changes in the Liver enzymes and Serum Bilirubin are transient as the values of LFT revert back to near pre-operative values by Post Op day-5. Hence Laparoscopic procedures can be safely performed in the absence of serious Liver disorders. However further studies are required in this regard.

\section{Conclusion}

In our study, that there was a transient elevation of hepatic enzymes and serum bilirubin in Laparoscopic Appendicectomy, Laparoscopic Cholecystectomy and Laparoscopic Umbilical hernia Mesh repair due to short-term reduction in hepatic blood flow, caused by $\mathrm{C} 02$ pneumoperitoneum. No apparent clinical changes were seen in the patients. Hence, as its benefits overcome its limitations, Laparoscopic surgery is soon emerging to be a gold standard for various surgical conditions. It is concluded that it is safe to perform Laparoscopic procedures in the presence of healthy liver. However it may not be safe to perform Laparoscopic surgeries in presence of serious Liver disorder.

\section{Summary}

- This is a prospective, observational and comparative study conducted in Department of General Surgery at Sri Adichunchanagiri Hospital and Research Center (AH \& RC), the teaching hospital attached to Adichunchanagiri Institute of Medical Sciences, B.G. Nagara, Mandya.

- Study sample consists of 100 patients who have undergone Laparoscopic procedures which include Laparoscopic Appendicectomy, Laparoscopic Cholecystectomy and Laparoscopic Umbilical hernia Mesh repair.

- Changes in the Liver function test were studied pre operatively, post-operative day-1 \& 5 among these patients.

- There was a transient changes in serum Bilirubin and Liver Enzymes in the POD-1 which reverted back to near normal to the pre-operative level by POD-5.

- There was no complication, no morbidity and no mortality.

- It is concluded that the changes in LFT is probably due to $\mathrm{CO} 2$ pneumoperitoneum.

- Laparoscopic procedures can be done safely in a patient in the presence of normal Liver function test and may not be safe in presence of serious Liver disorder.

- Since sample size is small in our study, further studies are required to support this study.

\section{References}

1. Tulikangas PK, Smith T, Falcone T, Boparai N, Walters MD. Gross and histologic characteristics of laparoscopic injuries with four different energy sources. Ferti Steril. 2001; 75:806-810.

2. Tauro LF, Sheetal CM, Aithala PSM, Shetty SR, D"esouza CS, Rao BSS, et al. Evaluation of effects of laparoscopic 
surgery on hepatic function. Journal of Clinical Diagnosis and Research. 2008; 2(6):1155-62.

3. Rikki Singal, Rajinder Pal Singal, Karamjot Sandhu, Bir Singh, Gaurav Bhatia, Abhishek Khatri, et al. Evaluation and comparison of postoperative levels of serum bilirubin, serum transaminases and alkaline phosphatase in laparoscopic cholecystectomy versus open cholecystectomy, J Gastrointest Oncol. 2015; 6(5):479-486.

4. Halevy A, Gold-Deutch R, Negri M, et al. Are elevated liver enzymes and bilirubin levels significant after laparoscopic cholecystectomy in the absence of bile duct injury? Ann Surg. 1994; 219(4):362-364.

5. Tan M, Xu FF, Peng JS, et al. Changes in the level of serum liver enzymes after laparoscopic surgery. World J Gastroenterol. 2003; 9(2):364-367.

6. George sakorafas, Vania statyla. Evaluation of serum liver enzymes after laparoscopic cholecystectomy NZ Med J, 118(1210), 1317.

7. Guven HE. Liver enzymes alterations after laparoscopic cholecystectomy. J Gastro intestine liver Dis. 2007; 16(4):391-4.

8. Dr. AM Syed Ibrahim MS. Dr. Venkata Bhargava Boppana2m.S, Dr. Manivannan Palani3 M.S. Evaluation of the Effects of Laparoscopic Surgeries on Hepatic Enzymes, IOSR-JDMS, e-ISSN: 2279-0853, p-ISSN: 2279-0861. 2017; 16(8):22-28.

9. Yang W, Benjamin IS, Sherwood R, Alexander B. Correlation of endothelium dependent and -independent vasodilatation with liver function tests during prolonged perfusion of the rat liver. J Pharmacol Toxicol Methods. 1998; 40:227-234. 